\title{
TIPOS DE ABORTO LEGAL
}

TYPES OF LEGAL ABORTION

Raphael Mendonça Costa ${ }^{1}$

ISSUE DOI: $10.21207 / 1983.4225 .332$

\section{RESUMO}

Este estudo apresenta as formas de aborto legal, ou seja, ocasiões em que a legislação brasileira permite a conduta tipificada no Código Penal, crime este ao qual se dá o nome de aborto. Antes de aprofundar no tema ora proposto, será feita uma breve apresentação dos vários tipos de aborto, e os mais diversos motivos aduzidos para a prática desta conduta típica. Após, já adentrando ao tema, será conceituado cada uma das modalidades de aborto permitido pelo ordenamento pátrio, sendo apresentados os requisitos para a realização das mesmas. Será feita, também, uma análise crítica de cada uma destas modalidades, apresentando argumentos utilizados para a defesa das mesmas, assim como os apresentados para criticá-las.

Palavras-chaves: Aborto Legal. Aborto Necessário. Aborto Sentimental. Aborto de Anencéfalo.

\section{ABSTRACT}

The purpose of this article is to order and explain the material and formal sources that have served as the basis for the definition of current fundamental rights as well as for human rights and fundamental theories themsel-

\footnotetext{
${ }^{1}$ Graduado em Direito pela Faculdade de Direito de Franca (2016). Advogado.
} 
ves. By qualitative method of legal and his- torical analysis, the main sources that based the understanding of the fundamental- ization of human rights are mapped, verifying the evolution of fundamental rights. The overall result of the research is the cognizance of the baselines influencing fundamental norms. As a specific result, the acquisition of parameters of reflection to reach the meaning and effectiveness of fundamental rights. Keywords: Material sources. Formal sources. Human rights. Fundamental rights.

\section{INTRODUÇÃO}

Um tema muito debatido na atualidade é em relação à legalização do aborto. Estudiosos do Direito confrontam seus argumentos buscando apoiar ou atacar a descriminalização da aludida conduta.

Saindo um pouco deste debate tão intenso e rico de argumentações de ambos os lados, o foco do presente estudo são as modalidades em que o nosso ordenamento autoriza a prática da aludida conduta, embora esta ainda seja tipificada como crime.

Serão apresentados os motivos para a descriminalização destas condutas em cada modalidade específica, buscando encontrar, de fato, a essência da norma permissiva, apresentando também os contra-argumentos dos que criticam este posicionamento, também pretendendo demonstrar sua real intenção.

Primeiramente, faz-se necessário conceituar o tipo em questão, apresentando as diversas modalidades de aborto, todas estas tidas como criminosas, para somente depois, desenvolver o tema central, de maneira mais aprofundada.

\section{CONCEITOS DE ABORTO}

No dicionário, o termo "abortar" é definido como "expulsar prematuramente do útero o produto da concepção". 2 Já o termo "aborto" é

\footnotetext{
2 FERREIRA, Aurélio Buarque de Holanda. Novo dicionário Aurélio da língua portuguesa. 4. ed. Curitiba: Positivo; 2009. p. 13.
} 
definido, na mesma obra, como "interrupção dolosa da gravidez, com expulsão do feto ou sem ela". ${ }^{3}$

Trazendo uma visão mais técnica, a doutrina brasileira define aborto como sendo "a interrupção do processo da gravidez, com a morte do feto.". 4

O aborto pode ser classificado, primeiramente, quanto a sua origem, em aborto natural, aborto acidental e o aborto provocado. Tanto o aborto natural como o acidental não constituem crime.

Nas palavras de Damásio E. de Jesus:

O aborto natural e o acidental não constituem crime. No primeiro, há interrupção espontânea da gravidez. $\mathrm{O}$ segundo geralmente ocorre em consequência de traumatismo. ${ }^{5}$

Como visto, o aborto natural e o acidental não são puníveis pelo Código Penal, restando a este apenas o aborto provocado. Insta frisar que o crime de aborto é punível apenas a título de dolo, mesmo que este seja genérico.

Já o aborto provocado pode ser definido como "o resultado de manobras praticadas deliberadamente com o fim de provocar a morte do concepto." ${ }^{6}$. É a esta modalidade que será aprofundada no presente trabalho.

Outra classificação possível é quanto à licitude do aborto, ou seja se é aborto legal ou criminoso. Cada uma destas modalidades será explicada em momento oportuno, começando pelas modalidades de aborto criminoso.

\footnotetext{
${ }^{3} 3$ FERREIRA, Aurélio Buarque de Holanda. Novo dicionário Aurélio da língua portuguesa. 4. ed. Curitiba: Positivo; 2009. p. 13

${ }^{4}$ DELMANTO, Celso et al. Código penal comentado. 6. Ed. atual. e ampl. Rio de Janeiro: Renovar, 2002. p. 268.

${ }^{5}$ JESUS, Damásio E. de. Código penal anotado: Damásio E. de Jesus. 17 ed. atual. São Paulo: Saraiva, 2005. pg. 431.

${ }^{6}$ MAGALHÃES, Leslei Lester dos Anjos. O princípio da dignidade da pessoa humana e 0 direito à vida. São Paulo: Saraiva, 2012. p. 115.
} 


\section{$2 \quad$ ABORTO CRIMINOSO}

\section{$2.1 \quad$ FIGURAS TÍPICAS DO ABORTO}

O crime de aborto é tipificado pelo Código Penal entre os arts. 124 e 127. Os aludidos dispositivos apresentam cinco figuras típicas: o aborto provocado pela própria gestante, conhecido como auto aborto (art. 124 primeira parte); com o consentimento da gestante para que outrem lhe provoque o aborto (art. 124 segunda parte); o aborto provocado por terceiro sem o consentimento da gestante (art. 125); o aborto provocado por terceiro com o consentimento da gestante (art. 126); e o aborto qualificado (art. 127). ${ }^{7}$

O objeto jurídico destas figuras típicas é sempre a vida do concepto e nos casos em que a gestante não for autora, a sua vida e incolumidade física também é tutelada pelo ordenamento jurídico. ${ }^{8}$

O sujeito ativo pode ser a própria gestante, nas modalidades previstas no art. 124, do CP, e qualquer outra pessoa nas demais figuras típicas. Já o sujeito passivo é sempre o concepto e, nos casos de aborto provocado por terceiro, a gestante. ${ }^{9}$

Vale ressaltar, que nos casos de aborto provocado por terceiro com o consentimento da gestante, será um caso de exceção pluralística a teoria monista, tendo em vista que a gestante responderá pelo crime do art. 124 , primeira parte, e o terceiro pelo crime tipificado no art. 126, ambos do CP. ${ }^{10}$

Este crime admite tentativa e a sua consumação se dá com a morte do feto ou a destruição do óvulo. ${ }^{11}$ É irrelevante o momento em que

\footnotetext{
${ }^{7}$ DELMANTO, Celso et al. Código penal comentado. 6. Ed. atual. e ampl. Rio de Janeiro: Renovar, 2002. p. 268.

${ }^{8}$ MASSON, Cleber. Código penal comentado. 2. ed. rev., atual. e ampl. - Rio de Janeiro: Forense; São Paulo: MÉTODO, 2014. p. 550.

${ }^{9}$ DELMANTO, Celso et al. Código penal comentado. 6. Ed. atual. e ampl. Rio de Janeiro: Renovar, 2002. p. 268.

${ }^{10}$ MASSON, Cleber. Código penal comentado. 2. ed. rev., atual. e ampl. - Rio de Janeiro: Forense; São Paulo: MÉTODO, 2014. p. 549.

${ }^{11}$ DELMANTO, Celso et al. Código penal comentado. 6. Ed. atual. e ampl. Rio de Janeiro: Renovar, 2002. p. 268. p. 268.
} 
ocorra a morte, que pode se dar tanto no ventre materno como em decorrência da expulsão do feto. ${ }^{12}$

\subsection{MODALIDADES DE ABORTO CRIMINOSO}

Agora serão apresentados alguns dos vários tipos de aborto, classificados quanto à sua motivação. Neste item, somente serão apresentados aqueles em que esta conduta é criminosa, ou seja, não há nenhum tipo de excludente sobre ela.

\subsubsection{Aborto Eugênico}

O aborto eugênico pode ser definido como:

É aquele praticado na presunção de que o futuro filho herdaria dos pais doenças ou anormalidades físicas ou mentais. Permite-o a legislação de diversos países. No Brasil, a permissão a esse tipo de aborto jamais encontrou guarida. ${ }^{13}$

Como se pode notar, nesses casos o aborto é motivado por alguma doença ou anomalia que o concepto venha a ter. Apesar de ser proibida, será analisado mais à frente o caso peculiar da anencefalia.

\subsubsection{Aborto Econômico}

Esta modalidade é praticada sobre a fundamentação de ser a família pobre e não ter condições de criar o filho que vai nascer e prejudicar

\footnotetext{
12 JESUS, Damásio E. de. Código penal anotado: Damásio E. de Jesus. 17 ed. atual. São Paulo: Saraiva, 2005. p. 431.

${ }^{13}$ PACHECO, Eliana Descovi. O aborto através dos tempos e seus aspectos jurídicos. Seção Revista Âmbito Jurídico. Disponível em: <http://www.ambito-juridico.com.br/site/?n_link=revista_artigos_leitura\&artigo_id=3740>. Acessado em: 24 de abril de 2016.
} 
a já difícil criação dos demais filhos já nascidos. ${ }^{14}$ Aqui não há justificativa quanto ao querer ou não dos pais, a única justificativa apresentada é a de que uma nova criança é economicamente inviável.

Insta frisar que esta modalidade de aborto, embora muito discutida, ainda é tida como crime.

\subsubsection{Aborto por comprometimento da saúde psíquica da mãe}

Aqui a justificativa é o abalo que a gestante sofrerá com a gestação e, se balizando nisto, resolve abortar. Sobre o tema vale ressaltar o seguinte entendimento:

As alterações psíquicas originadas com a gravidez são um risco de toda maternidade. Ademais, sabemos que os distúrbios causados nas mulheres pelo próprio abortamento é muito maior do que se sofre para sustentar a vida do filho, e especialmente o remorso das mulheres que abortam traz problemas psicológicos sérios. ${ }^{15}$

Nesta modalidade não é a saúde física que está em jogo, e sim a saúde mental da gestante. Os distúrbios emocionais causados não chegam a apresentar um grave risco para a vida da gestante, e por isso, não encontram respaldo na legislação pátria.

\subsubsection{ABORTO POR GRAVIDEZ INDESEJADA}

Esta é certamente a justificativa mais utilizada pelas gestantes que recorrem a este tipo de procedimento. Independentemente do motivo,

\footnotetext{
14 MARTINS, Ives Gandra da Silva (coordenação). Direito fundamental à vida. São Paulo: Quartier Latin/ Centro de Extensão Universitária, 2005. p. 547.

${ }^{15}$ CLOWES, Brian, apud MAGALHÃES, Leslei Lester dos Anjos. O princípio da dignidade da pessoa humana e o direito à vida. São Paulo: Saraiva, 2012. p. 115.
} 
por serem novas, por atrapalhar os estudos, por não quererem se comprometer com o pai ou para fugir das responsabilidades de um filho, o fato é que esta gravidez não é desejada pela gestante e por isso ela pretende abortar.

Nas palavras de Leslei Lester dos Anjos Magalhães:

O aborto, nestes casos, é a fuga à responsabilidade pelo sexo livre, fora do casamento, ou pior, a recusa do casal unido em matrimônio de arcar com as responsabilidades de um novo filho. ${ }^{16}$

\section{ABORTO LEGAL}

Apesar de ser uma conduta típica, existem ocasiões em que, pelas suas peculiaridades, a legislação afasta a ilicitude da conduta, tornando-se assim, um tipo de aborto legal.

Como será visto adiante, a legislação traz alguns requisitos para que seja realmente legal esta prática, como por exemplo, que o aborto seja realizado por médico capacitado para a realização do ato com segurança para a gestante.

No Brasil, apenas em três ocasiões o aborto é aceito pelo ordenamento jurídico: nos casos de risco de vida da gestante, nos casos de gravidez por estupro e nos casos de anencefalia. Nas duas primeiras ocasiões, o próprio Código Penal apresenta estas exceções, e na última, a autorização é dada por um julgado do STF.

Será feita agora uma análise mais profunda de cada uma destas modalidades de aborto legal, sendo apresentados os argumentos utilizados pelos defensores, assim como pelos opositores destas modalidades.

\subsection{ABORTO POR RISCO DE VIDA PARA A GESTANTE}

\footnotetext{
${ }^{16}$ MAGALHÃES, Leslei Lester dos Anjos. O princípio da dignidade da pessoa humana e o direito à vida. São Paulo: Saraiva, 2012. p.131.
} 
Também conhecido como aborto terapêutico ou aborto necessário, esta modalidade encontra-se prevista expressamente no art. 128, inciso I do Código Penal Brasileiro. Trata-se de uma causa excludente da ilicitude da conduta. ${ }^{17}$

Aqui se autoriza o aborto quando a vida da gestante estiver correndo risco e não houver outra maneira de salvá-la. Aqui pode-se fazer um comentário, visto que esta previsão se torna desnecessária, porque mesmo que não fosse prevista esta modalidade, autorizado estaria o médico a atuar, tendo em vista que se encontram presentes os elementos do estado de necessidade, que é uma excludente de ilicitude genérica, tanto que é desnecessário a autorização da gestante. ${ }^{18}$

Na verdade, o que ocorre aqui é um conflito de direitos em que se tem de um lado o direito à vida do concepto, e de outro o direito à vida da gestante. Tendo em vista que, dependendo da fase em que se encontra a gestação, a continuidade da vida do feto tem uma forte relação de dependência com a vida da gestante, a lei autoriza o aborto.

Outro ponto levado em consideração é um jogo de possibilidades em que de um lado, ao interromper a gestação, se garante a vida da gestante, esta já certa e desenvolvida, e do outro, sem que a gestação seja interrompida, uma possibilidade de se ter ambos os envolvidos vivos, mas com a possibilidade também de se ter ambos mortos. Ou seja, ao agir, se garante a vida da gestante e permanecendo inerte, oscila entre salvar e perder todos.

A justificativa que se dá para o fato de ser dispensável o consentimento da gestante é que a vida é um bem indisponível. ${ }^{19}$ Sendo assim, a gestante não pode decidir arriscar a sua vida para tentar salvar a vida do concepto. Vale ressaltar que o art. $146, \S 3^{\circ}$, inciso I, do CP, autoriza a intervenção cirúrgica sem o consentimento do paciente, ou representante legal, em casos em que há risco de vida.

${ }^{17}$ CAPEZ, Fernando. Código penal comentado. 3. ed - São Paulo: Saraiva, 212. p. 339

${ }^{18}$ MASSON, Cleber. Código penal comentado. 2. ed. rev., atual. e ampl. - Rio de Janeiro: Forense; São Paulo: MÉTODO, 2014. p.555.

${ }^{19}$ MOURA, Angela Acosta Giovanini de. A eutanásia e o direito à vida. Disponível em: <http://www.jurisway.org.br/v2/dhall.asp?id_dh=3097>. Acessado em: 28 de abril de 2016. 


\subsubsection{Argumentos a favor do aborto terapêutico}

O principal argumento utilizada na defesa desta modalidade é justamente o fato de que se não houvesse a previsão desta possibilidade, ainda sim o resultado seria o mesmo, qual seja, o médico deverá atuar e a conduta será totalmente lícita.

Insta frisar, primeiramente, que se trata de uma excludente de ilicitude especial, na qual exige para a sua configuração risco de vida da gestante em razão da gestação e inexistência de outro meio capaz de salvála. ${ }^{20}$

Ora, se trata-se de uma modalidade específica, ela está inclusa em uma modalidade genérica. Sendo assim, esta excludente especial, também preenche os requisitos do estado de necessidade, excludente de ilicitude previsto no art. 24, do CP. Para a configuração desta é necessário: atualidade do perigo, inevitabilidade do perigo e inevitabilidade da lesão, involuntariedade na causação do perigo, inexigibilidade do sacrifício do bem ameaçado e por fim o conhecimento da situação justificadora da conduta. $^{21}$

A gravidez de risco trata-se de perigo certo e atual, inevitável, alheia à vontade da gestante e o sacrifício da "vida" do concepto para salvar a vida da gestante se mostra razoável, estando configurado assim o estado de necessidade previsto no dispositivo legal supracitado.

\subsubsection{Argumentos contra aborto terapêutico}

Os principais críticos deste dispositivo são principalmente os adeptos à teoria concepcionista. Alguns criticam até a nomenclatura dada, a expressão aborto "terapêutico", pois segundo estes, “(...) o objeto do ato, morte deliberada de uma vida humana, não pode ter a sua natureza mudada pela intenção "boa" do executor". ${ }^{22}$

\footnotetext{
${ }^{20}$ MASSON, Cleber. Código penal comentado. 2. ed. rev., atual. e ampl. - Rio de Janeiro: Forense; São Paulo: MÉTODO, 2014. p. 555.

${ }^{21}$ TUPY, Igor Bertoli. Estado de necessidade. Disponível em: <https://jus.com.br/artigos/4711/estado-de-necessidade>. Acessado em: 24 de abril de 2016.

${ }^{22}$ MAGALHÃES, Leslei Lester dos Anjos. O princípio da dignidade da pessoa humana e o direito à vida. São Paulo: Saraiva, 2012. p.126.
} 
O que se critica, de fato, é que para evitar uma morte acaba ocasionando-se outra. Em outras palavras, para evitar uma morte, se mata alguém.

Outros criticam o dispositivo, estes de maneira mais branda, dizendo que diante de uma situação extremamente necessária, em que o aborto se mostra como única alternativa, o médico responsável deve chamar em conferência outro médico, de idoneidade reconhecida, para tomar a sua opinião e se entrarem em acordo, aí sim este poderá efetuar a intervenção na gestação. ${ }^{23}$

Os defensores desta tese ainda afirmam que o abortamento terapêutico não se justifica, pois, em primeiro lugar, a morte da gestante é apenas uma possibilidade, corre risco e não está condenada à morte; em segundo lugar, os progressos da medicina reduzem cada vez mais os riscos à gestante; e por último, o próprio aborto gera riscos à gestante, sendo em inúmeros casos a causa da morte da gestante o próprio abortamento. ${ }^{24}$

Como dito, os principais críticos desta tese são os defensores da teoria concepcionista, dentre eles, os católicos de modo geral. Inclusive na Evangelium Vitae, n. ${ }^{\circ} 70$ está escrito que:

Quando uma maioria parlamentar ou social decreta a legitimidade da eliminação, mesmo sob certas condições, da vida humana ainda não nascida, assume uma decisão tirânica contra o ser humano mais débil e indefeso ${ }^{25}$

Por fim, buscando afastar a tese de que a vida do concepto depende da vida da gestante, Leslei Lester dos Anjos Magalhães afirma que:

Caso morra a mãe antes do parto, a medicina atual tem conseguido manter artificialmente as funções vitais da mãe, possibilitando o desenvolvimento do bebê,

\footnotetext{
${ }^{23}$ MARTINS, Ives Gandra da Silva (coordenação). Direito fundamental à vida. São Paulo: Quartier Latin/Centro de Extensão Universitária, 2005. p.548.

${ }^{24}$ MAGALHÃES, Leslei Lester dos Anjos. O princípio da dignidade da pessoa humana e o direito à vida. São Paulo: Saraiva, 2012. p.126.

${ }^{25}$ DIAS, João Silva. Vencer a cultura da morte com o "Evangelho da Vida". Disponível em: 〈http://www.santidade.net/artigos/jsd_evangelho_vida.pdf>. Acessado em: 25 de abril de 2016.
} 
até uma fase em que seja garantida uma vida autônoma. ${ }^{26}$

\subsection{ABORTO POR ESTUPRO}

O aborto no caso de gravidez resultante de estupro, também conhecido como aborto sentimental ou humanitário, é aquele, como o próprio nome diz, em que a gestação é resultante de uma violação sexual, o crime de estupro previsto no art. 213, do CP.

Para a configuração do crime de aborto são necessários dois requisitos: primeiro, que a gravidez seja resultante de estupro e segundo, que haja consenso prévio da gestante ou de seu representante legal. ${ }^{27}$

A natureza jurídica desta excludente é, majoritariamente, definida como sendo um exercício regular de um direito, porém há doutrinadores que acreditam que se trata de uma exclusão de tipicidade, aplicando a teoria da tipicidade conglobante. ${ }^{28}$

Sendo assim, aplicando a teoria supracitada temos que:

(...) a tipicidade de um determinado fato há de ser avaliada de maneira global, o que leva necessariamente à análise de todo o ordenamento jurídico. Logo, se o ordenamento proíbe o estupro, por óbvio não poderia forçar sua vítima a aceitar o resultado desta prática, pelo quê, a interrupção da gravidez nesta hipótese não poderia ser proibida, e por este motivo, o abortamento humanitário é atípico. ${ }^{29}$

\footnotetext{
${ }^{26}$ MAGALHÃES, Leslei Lester dos Anjos. O princípio da dignidade da pessoa humana e o direito à vida. São Paulo: Saraiva, 2012. p.127.

27 JESUS, Damásio E. de. Código penal anotado: Damásio E. de Jesus. 17 ed. atual. São Paulo: Saraiva, 2005. p. 438.

${ }^{28}$ GOMES, Luiz Flávio. Data vênia: aborto humanitário ou sentimental. Exclusão da tipicidade. Disponível em: <http://lfg.jusbrasil.com.br/noticias/2460058/data-veniaaborto-humanitario-ou-sentimental-exclusao-da-tipicidade>. Acessado em: 28 de abril de 2016.

${ }^{29}$ GOMES, Luiz Flávio. Data vênia: aborto humanitário ou sentimental. Exclusão da tipicidade. Disponível em: <http://lfg.jusbrasil.com.br/noticias/2460058/data-venia-
} 
Alguns doutrinadores ressaltam que quando a codificação foi editada, a mulher somente podia figurar como vítima deste crime, porém com a nova redação dada ao dispositivo que prevê o crime de estupro, a mulher também pode figurar como autora, sendo debatido a aplicabilidade da excludente prevista no art. 128 , inciso II, do CP. ${ }^{30}$

Frisa-se que para a correta aplicação desta excludente, não é necessário que haja processo penal pelo crime de estupro e, tampouco, uma sentença penal condenatória pelo mesmo, basta a existência de provas seguras acerca da existência do crime de estupro. ${ }^{31}$

Por fim vale ressaltar que para que a prática prevista no dispositivo ora analisado aconteça, é necessário que seja praticado por médico, sendo ilícito o aborto realizado por outro profissional ou pela própria gestante, ainda que nos casos de gravidez resultante de estupro. ${ }^{32}$

\subsubsection{Argumentos a favor do aborto humanitário}

Como principal fundamento do aborto humanitário é invocado o princípio da dignidade da pessoa humana, pois não seria digno exigir da mulher, vítima de um crime tão cruel como o aborto, ter que ver o seu corpo mudando, sofrendo com todos os infortúnios que uma gestação causa, sem desejar e amar a criança que está por vir.

A doutrina salienta que:

Inevitável lembrar que a ideia que ampara o aborto sentimental é a de impedir que a mulher carregue em seu ventre o fruto da concepção indesejada, resultado de prática violenta, à qual ela foi constrangida, e

aborto-humanitario-ou-sentimental-exclusao-da-tipicidade>. Acessado em: 28 de abril de 2016.

${ }^{30}$ OLIVEIRA, Flavio Cardoso de, et al. O aborto sentimental e a interrupção da gravidez da autora do crime de estupro. Disponível em: <http://www.migalhas.com.br/dePeso/16,MI128200,91041-O+aborto+sentimental+e+a+interrupcao+da+gravidez+da+autora+do+crime>. Acessado em: 26 de abril de 2016.

${ }^{31}$ JESUS, Damásio E. de. Código penal anotado: Damásio E. de Jesus. 17 ed. atual. São Paulo: Saraiva, 2005. p.438.

${ }^{32}$ MASSON, Cleber. Código penal comentado. 2. ed. rev., atual. e ampl. - Rio de Janeiro: Forense; São Paulo: MÉTODO, 2014. p.555. 
também evitar que, caso o nascimento ocorra, seja ela obrigada a conviver com um filho que vai lhe fazer se lembrar, por toda a vida, da violação que sofreu. ${ }^{33}$

Da mesma maneira, o princípio da dignidade humana pode ser utilizado para proteção do concepto, pois ele vai se desenvolver e, em determinado ponto, saberá que é fruto de um crime, o que poderá afetar o seus desenvolvimento psíquico. Também se podem citar problemas relacionados ao ramo do Direito de Família, pois esta criança pode vir a procurar o seu genitor, querer, e ter o direito de ter contato com o genitor/criminoso.

Veja que aqui não há um conflito entre vida e vida, e sim, de um lado, o direito à vida do concepto e, de outro, a dignidade da pessoa humana da gestante. Forçar a mãe a levar esta gestação a termo é obrigá-la a reviver diariamente, por pelo menos nove meses, os momentos traumáticos vividos no momento da concepção do feto.

Com a disseminação dos métodos anticoncepcionais, tais como o anticoncepcional utilizado por boa parte da população feminina, ou a "pílula do dia seguinte", que poderia ser utilizada após o crime de estupro para evitar a gestação, pode-se incorrer no erro de pensar que os casos práticos de aplicação desta norma permissiva são raros, porém não é o caso.

Existem inúmero casos em que a mulher é sequestrada, sofrendo estupros repetidamente por vários dias até que, independentemente do motivo, cessem estes estupros. A este ponto, já não adianta "pílula do dia seguinte" e por vezes o anticoncepcional que ela possa estar tomando, já não tem a mesma eficácia.

É com o pensamento nestas mulheres, que foram vítimas de um dos crimes mais brutais previstos no nosso ordenamento, que foram rebaixadas à qualidade de objeto sexual, que esta norma permite o aborto nestes casos, tentando reestabelecer a sua dignidade, e preservar, ou no mínimo poupar, a sua saúde mental.

\footnotetext{
${ }^{33}$ OLIVEIRA, Flavio Cardoso de, et al. O aborto sentimental e a interrupção da gravidez da autora do crime de estupro. Disponível em: <http://www.migalhas.com.br/dePeso/16,MI128200,91041-O+aborto+sentimental+e+a+interrupcao+da+gravidez+da+autora+do+crime>. Acessado em: 26 de abril de 2016.
} 


\subsubsection{Argumentos contra o aborto humanitário}

Da mesma maneira que no caso do aborto necessário, os críticos desta norma permissiva, na maioria dos casos, defensores da teoria concepcionista, invocam o direito à vida como forma de questionar este dispositivo.

Sobre o Direito à Vida, frisa-se a seguinte frase de Thomas de Koninck:

Todo ser humano, qualquer que seja ele, possui uma dignidade própria ...: ela está acima de todo preço e não admite qualquer equivalência, não tendo um valor relativo mas um valor absoluto. ${ }^{34}$

Outro ponto questionado em relação ao dispositivo em análise é no tocante à constitucionalidade do mesmo, confrontando o art. 128, inciso II, do CP e o art. $5^{\circ}$ da Constituição da República.

O Código Penal foi elaborado antes da promulgação da Carta Magma de 1988, sendo assim, ao ser promulgada, a Constituição Federal não recepcionou o dispositivo ora analisado, encontrando-se o mesmo na condição de inconstitucional, segundo este entendimento. ${ }^{35}$ Veja que, mais uma vez, aqui é invocado o direito à vida do feto para se criticar esta permissiva.

Outro ponto muito criticado neste dispositivo é entre a discrepância do que ocorre ao genitor/estuprador e o concepto. Os doutrinadores que criticam esta norma alegam que, "a criança inocente acaba sendo penalizada por um ato ilícito de seu pai e a pena cruelmente executada é a de morte". 36

O dualismo se dá no fato de que o estuprador, caso venha a ser preso, responderá por uma pena privativa de liberdade, entre seis e dez

\footnotetext{
${ }^{34}$ KONINCK, Thomas de, apud MARTINS, Ives Gandra da Silva (coordenação). Direito fundamental à vida. São Paulo: Quartier Latin/Centro de Extensão Universitária, 2005. p. 548.

${ }^{35}$ CAROLLO, João Carlos. A inconstitucionalidade do art. 128, inciso II do código penal. Disponível em: <http://www.debatecomprofessores.com/2011/11/inconstitucionalidade-do-art-128-ii-do.html>. Acessado em 26 de abril de 2016.

${ }^{36}$ MAGALHÃES, Leslei Lester dos Anjos. O princípio da dignidade da pessoa humana e o direito à vida. São Paulo: Saraiva, 2012.
} 
anos, já o feto, totalmente inocente, gerado a partir desta conduta criminosa, será "condenado à morte".

O que se critica é justamente esta discrepância entre o destino do criminoso e o destino do feto. Porém, este parecer não leva em consideração o futuro da mulher gestante que, assim como o feto, também é vítima deste crime terrível e, foi justamente pensando nela, que o legislador autorizou este tipo de aborto.

\subsection{ABORTO NOS CASOS DE ANENCEFALIA}

Esta modalidade não está prevista no Código Penal brasileiro, sendo o resultado de uma ação proposta perante o Supremo Tribunal Federal. Esta modalidade autoriza o "aborto" nos casos de anencefalia. É uma das permissões mais discutidas na modernidade no tocante à legalização do aborto, e de outros temas correlatos.

A Arguição de Descumprimento de Preceito Fundamental 54 (ADPF 54) foi proposta perante o STF, pelo Conselho Nacional dos Trabalhadores na Saúde (CNTS), com o objetivo de que o Tribunal impossibilite o enquadramento da interrupção terapêutica de gestação nos casos de anencefalia, nos crimes tipificados nos arts. 124 e 126 do CP.

Anencefalia é definida como a "má-formação fetal congênita por defeito do fechamento do tubo neural durante a gestação, de modo que o feto não apresenta os hemisférios cerebrais e o córtex, havendo apenas resíduo do tronco encefálico". 37

Desta maneira, devida a esta malformação do tubo neural, o STF declarou a inconstitucionalidade da interpretação segundo a qual a interrupção terapêutica da gestação, nos casos de anencefalia, possa ser enquadrada nos crimes tipificados nos arts. 124 e seguintes do CP. ${ }^{38}$

\footnotetext{
${ }^{37}$ BRASIL. Supremo Tribunal Federal. Arguição de descumprimento de preceito fundamental no 54/DF - Distrito Federal. Relator: Ministro Marco Aurélio. Pesquisa de Jurisprudência, Acórdãos, 09 abril 2012. Disponível em: < http://www.stf.jus.br/portal/jurisprudencia/pesquisarJurisprudencia.asp>. Acesso em: 10 agosto 2015.

${ }^{38}$ GUASQUE, Adriane. Aborto de anencéfalos: direito à vida e impacto sucessórios. Disponível em: <http://www.ambito-juridico.com.br/site/index.php?artigo_id=11924\&n_link=revista_artigos_leitura $>$. Acessado em: 26 de abril de 2016.
} 
Os fundamentos invocados para proclamar esta decisão foram a laicidade do Estado, a dignidade da pessoa humana, o usufruto da vida, a liberdade, a autodeterminação, a saúde e o pleno reconhecimento dos direitos individuais, especialmente os direitos sexuais e reprodutivos das mulheres. ${ }^{39}$

\subsubsection{Argumentos a favor do aborto de anecénfalos}

Esclarecido o que é a anencefalia, insta frisar que no Brasil o aborto eugênico, aquele o qual é praticado sob a justificativa de que o feto é portador de defeitos físicos ou mentais, ou de alguma anomalia ${ }^{40}$, é terminantemente proibido.

Pode parecer contraditório o aborto eugênico ser proibido e nos casos de anencefalia ser permitido, porém a justificativa é que, segundo o entendimento do STF, a anencefalia é incompatível com a vida humana.

Nesta mesma linha de raciocínio está o relator Marco Aurélio que diz:

Aborto é crime contra a vida. Tutela-se a vida em potencial. No caso do anencéfalo, não existe vida possível. O feto anencéfalo é biologicamente vivo, por ser formado por células vivas, e juridicamente morto, não gozando de proteção estatal. [...] $\mathrm{O}$ anencéfalo jamais se tornará uma pessoa. Em síntese, não se cuida de vida em potencial, mas de morte segura. Anencefalia é incompatível com a vida. ${ }^{41}$

Sendo assim, um primeiro argumento utilizado para a manutenção desta permissiva, é o fato de que o anencéfalo não possui vida humana. Desta maneira, a conduta que provoca a antecipação do parto nos casos de

\footnotetext{
${ }^{39}$ MASSON, Cleber. Código penal comentado. 2. ed. rev., atual. e ampl. - Rio de Janeiro: Forense; São Paulo: MÉTODO, 2014. p. 556

${ }^{40}$ Ibidem.

${ }^{41}$ BRASIL. Supremo Tribunal Federal. Arguição de descumprimento de preceito fundamental no 54/DF - Distrito Federal. Relator: Ministro Marco Aurélio. Pesquisa de Jurisprudência, Acórdãos, 09 abril 2012. Disponível em: < http://www.stf.jus.br/portal/jurisprudencia/pesquisarJurisprudencia.asp>. Acesso em: 10 agosto 2015.
} 
anencefalia não pode ser enquadrada em um crime contra à vida já que esta, na acepção técnica do termo, não existe.

Sendo assim, não se reconhecendo a vida do feto, e consequentemente, não tendo estes direitos, devem prevalecer os direitos à liberdade da gestante de determinar-se a respeito de seu próprio corpo, e escolher se quer ou não levar a gestação a termo.

Nesta mesma linha de raciocínio, tem-se uma das frases mais marcantes no julgamento da ADPF 54, prolatada pelo relator o Ministro Marco Aurélio que segue:

Ora, inexistindo potencialidade para tornar-se pessoa humana, não surge justificativa para a tutela jurídicopenal, com maior razão quando eventual tutela esvarra em direitos fundamentais da mulher, como se verá adiante. Enfim, cumpre tomar de empréstimo o conceito jurídico de morte cerebral previsto na Lei 9.434/1997, para concluir ser de todo impróprio falar em direito à vida intrauterina ou extrauterina do anencéfalo, o qual é um natimorto cerebral. ${ }^{42}$

Veja a profundidade da expressão utilizada pelo Excelentíssimo Relator, "natimorto cerebral". Note que mesmo se desenvolvendo, crescendo, o fato de não possuir cérebro coloca o feto na condição de natimorto.

Desta maneira, não tendo um feto titular de direitos, a única solução plausível é a autorização desta prática, pois obrigar a mulher a preservar a gestação produz danos à gestante, podendo abalar seriamente o seu psicológico, podendo predominar casos mórbidos de dor, angústia, luto, impotência e desespero, em face da certeza do óbito. ${ }^{43}$

\footnotetext{
${ }^{42}$ BRASIL. Supremo Tribunal Federal. Arguição de descumprimento de preceito fundamental no 54/DF - Distrito Federal. Relator: Ministro Marco Aurélio. Pesquisa de Jurisprudência, Acórdãos, 09 abril 2012. Disponível em: < http://www.stf.jus.br/portal/jurisprudencia/pesquisarJurisprudencia.asp>. Acesso em: 10 agosto 2015.

${ }^{43}$ MASSON, Cleber. Código penal comentado. 2. ed. rev., atual. e ampl. - Rio de Janeiro: Forense; São Paulo: MÉTODO, 2014. p.556.
} 


\subsubsection{Argumentos contra o aborto de anencéfalos}

Uma das grandes críticas que se faz a esta permissiva é que, como dito, uma das fundamentações da autorização, é o fato de que "não há expectativa de vida, mas uma certeza de morte". ${ }^{44}$ Assim, a crítica que se faz é uma comparação com a eutanásia, em que se tem um quadro de morte certa e iminente, muitas vezes com uma morte sofrida.

Dessa maneira, defender a legalidade e a constitucionalidade do aborto de anencéfalos com o fundamento de que estes já estão com a morte iminente e certa, seria, para estes estudiosos, o mesmo que defender o direito à morte dos doentes terminais. ${ }^{45}$

Sobre esse tema, também há doutrinadores que afirmam que há um direito do ser humano de ter uma morte natural. ${ }^{46}$ Todos têm direito a ter uma morte digna, que no caso, significa a morte natural. Segundo essa linha de pensamento, não seria digno antecipar a morte de um moribundo, assim como não seria antecipar a "morte" do anencéfalo.

O grande empecilho para que esta tese prospere, é o fato de que, segundo os conceitos trazidos pela Lei de Transplante de Órgãos, o anencéfalo já é considerado um ser sem vida.

Paulo Silveira Martins Leão Júnior, porém, afirma com todas as letras que "A anencefalia não significa morte cerebral". ${ }^{47} \mathrm{Na}$ mesma oportunidade, o autor, tomando por base documento elaborado por comissão de especialistas e aprovado pelo Comitê Nacional de Bioética da Itália, recorta um trecho do aludido documento, que segue:

Apesar de uma expectativa de vida tão reduzida não é sempre possível definir a iminência do óbito e a

\footnotetext{
${ }^{44}$ BRASIL. Supremo Tribunal Federal. Arguição de descumprimento de preceito fundamental no 54/DF - Distrito Federal. Relator: Ministro Marco Aurélio. Pesquisa de Jurisprudência, Acórdãos, 09 abril 2012. Disponível em: < http://www.stf.jus.br/portal/jurisprudencia/pesquisarJurisprudencia.asp >. Acesso em: 10 agosto 2015.

${ }^{45}$ MAGALHÃES, Leslei Lester dos Anjos. O princípio da dignidade da pessoa humana e o direito à vida. São Paulo: Saraiva, 2012. p.128.

${ }^{46}$ Ibidem. p. 104.

47 MARTINS, Ives Gandra da Silva (coordenação). Direito fundamental à vida. São Paulo: Quartier Latin/Centro de Extensão Universitária, 2005. p.244.
} 
duração da vida pode ser influenciada em muito pelos tratamento intensivos. ${ }^{48}$

Aqui abre-se um parêntese para discordar do posicionamento supracitado. Para tanto, valendo-se de conceito de morte cerebral trazida pela Lei de Transplante de Órgãos, é possível fazer um paralelo entre o anencéfalo e a pessoa que se encontra em estado de morte cerebral, mas é mantida viva com a ajuda de aparelhos. A gestante exerce para o anencéfalo a mesma função que os aparelhos para quem teve a sua morte cerebral decretada. $\mathrm{O}$ anencéfalo depende da gestante para manter o seu corpo funcionando, assim como outro depende dos aparelhos, e uma vez rompida esta ligação, ambos os corpos irão morrer, mas a pessoa que sofreu de morte cerebral está inegavelmente morta, não seria o mesmo o que ocorre com o anencéfalo?

Mesmo que a gestação venha a termo, e o feto venha a nascer, este somente continuará "vivo" com a ajuda de aparelhos, ficando na mesma posição que a pessoa que teve a sua morte cerebral decretada. Se este está morto, o anencéfalo também está dentro ou fora do útero materno.

Desta maneira, não há como reconhecer a vida humana nos anencéfalos, pelo menos não com a atual legislação que, de maneira indireta, reflete sobre o tema. O que se tem é única e exclusivamente vida biológica em um corpo humano, o que não se confunde com vida humana.

\section{CONSIDERAÇÕES FINAIS}

Afastando-se da grande temática que é a legalização, ou não, do aborto, houve a restrição de falar sobre os tipos de aborto, tratando com mais cuidado os tipos de aborto legal.

Apesar de ainda ser criminalizada a prática do aborto, existem ocasiões em que ela é autorizada, sendo que nestes casos o direito à vida do concepto acaba ficando em segundo plano, prevalecendo outros direitos de titularidade da gestante, tais como o direito à liberdade, o direito à saúde e o próprio direito à vida.

\footnotetext{
48 MARTINS, Ives Gandra da Silva (coordenação). Direito fundamental à vida. São Paulo: Quartier Latin/Centro de Extensão Universitária, 2005. p. 246.
} 
Dos três tipos de aborto legal, dois estão previstos expressamente em nossa legislação: o aborto nos casos de estupro e nos casos de gravidez de risco, e um foi autorizado por uma ação proposta diretamente perante o STF, a ADPF 54, que acabou por permitir a interrupção terapêutica da gestação nos casos de anencefalia.

Neste último julgado, em especial, parece que o STF está se filiando à corrente de que a vida humana do feto na gestação somente se inicia com o desenvolvimento do sistema nervoso central. Isto porque, se o anencéfalo não possui vida por não possuir cérebro, como dito é um "natimorto cerebral", não é a fecundação ou a nidação que vai dar início à vida humana, mas esta se dá somente com a formação do cérebro.

Sendo assim, este julgado pode abrir uma válvula de modo que possa vir a se descriminalizar e regulamentar o aborto no país, pois não havendo vida do concepto até o desenvolvimento do sistema nervoso central, não haveria, até este momento, embate de direitos, mas somente os direitos da mãe de decidir ou não continuar com a gestação.

\section{REFERÊNCIAS BILIOGRÁFICAS}

BRASIL. Supremo Tribunal Federal. Arguição de descumprimento de preceito fundamental $\mathbf{n}^{\mathbf{0}}$ 54/DF - Distrito Federal. Relator: Ministro Marco Aurélio. Pesquisa de Jurisprudência, Acórdãos, 09 abril 2012. Disponível em: $<$ http://www.stf.jus.br/portal/jurisprudencia/pesquisarJurisprudenc ia.asp>. Acesso em: 10 agosto 2015.

CAPEZ, Fernando. Código penal comentado. 3. ed - São Paulo: Saraiva, 212.

CAROLLO, João Carlos. A inconstitucionalidade do art. 128, inciso II do código penal. Disponível em: <http://www.debatecomprofessores.com/2011/11/inconstitucionali dade-do-art-128-ii-do.html >. Acessado em 26 de abril de 2016.

DELMANTO, Celso et al. Código penal comentado. 6. Ed. atual. e ampl. Rio de Janeiro: Renovar, 2002.

DIAS, João Silva. Vencer a cultura da morte com o "Evangelho da Vida". Disponível em: <http://www.santidade.net/artigos/jsd_evangelho_vida.pdf $>$. Acessado em: 25 de abril de 2016. 
FERREIRA, Aurélio Buarque de Holanda. Novo dicionário Aurélio da língua portuguesa. 4. ed. Curitiba: Positivo; 2009.

GOMES, Luiz Flávio. Data vênia: aborto humanitário ou sentimental. Exclusão da tipicidade. Disponível em: <http://lfg.jusbrasil.com.br/noticias/2460058/data-venia-abortohumanitario-ou-sentimental-exclusao-da-tipicidade>. Acessado em: 28 de abril de 2016.

GUASQUE, Adriane. Aborto de anencéfalos: direito à vida e impacto sucessórios. Disponível em: <http://www.ambitojuridico.com.br/site/index.php?artigo_id=11924\&n_link=revista_ar tigos_leitura>. Acessado em: 26 de abril de 2016.

JESUS, Damásio E. de. Código penal anotado: Damásio E. de Jesus. 17 ed. atual. São Paulo: Saraiva, 2005.

MAGALHÃES, Leslei Lester dos Anjos. O princípio da dignidade da pessoa humana e o direito à vida. São Paulo: Saraiva, 2012.

MARTINS, Ives Gandra da Silva (coordenação). Direito fundamental à vida. São Paulo: Quartier Latin/ Centro de Extensão Universitária, 2005.

MASSON, Cleber. Código penal comentado. 2. ed. rev., atual. e ampl. Rio de Janeiro: Forense; São Paulo: MÉTODO, 2014.

MOURA, Angela Acosta Giovanini de. A eutanásia e o direito à vida. Disponível

em: <http://www.jurisway.org.br/v2/dhall.asp?id_dh=3097>. Acessado em: 28 de abril de 2016.

OLIVEIRA, Flavio Cardoso de, et al. O aborto sentimental e a interrupção da gravidez da autora do crime de estupro. Disponível

em:

<http://www.migalhas.com.br/dePeso/16,MI128200,91041-

O+aborto+sentimental+e+a+interrupcao+da+gravidez+da+autora+ do+crime>. Acessado em: 26 de abril de 2016.

PACHECO, Eliana Descovi. O aborto através dos tempos e seus aspectos jurídicos. Seção Revista Âmbito Jurídico. Disponível em: $<$ http://www.ambitojuridico.com.br/site/?n_link=revista_artigos_leitura\&artigo_id=374 0>. Acessado em: 24 de abril de 2016.

TUPY, Igor Bertoli. Estado de necessidade. Disponível em: $<$ https://jus.com.br/artigos/4711/estado-de-necessidade>. Acessado em: 24 de abril de 2016. 
